\section{Nurses and abortion}

Vincent Argent and Lin Pavey have concluded, in an analysis of the House of Lords case Royal College of Nursing v DHSS [1981] 1 AC 800 ("the RCN case"), that without any change in the law, nurses can legally perform surgical induced abortion. ${ }^{1}$ Their article contains some dangerous legal misconceptions.

The RCN case concerned the participation of nurses in prostaglandin-induced abortions. The House of Lords decided by a majority $(3: 2)$ that in certain circumstances nurses could participate.

The RCN case decided that for the procedure that the court was considering:

(a) Medical abortion is a process

(b) The process may be effected by a team.

(c) Section 1(1) of the Abortion Act 1967 permits delegation to nurses of some acts which form part of the process. This includes acts that have a direct abortifacient effect.

(d) The process must be initiated by a registered medical practitioner, and must be under his control throughout, in the sense that anything done other than by him must be done pursuant to his instructions.

(e) What amounts to acceptable delegation may be determined by "accepted medical practice"

One of the judges in the majority, Lord Keith, expressly regarded the decision as one on its own facts. He said: “...it remains to consider whether, on the facts of this case the termination can properly be regarded as being "by a registered medical practitioner"2 [emphasis my own]. This means that when considering an abortion procedure, unless one is dealing with precisely the procedure that the $\mathrm{RCN}$ case considered, it cannot be asserted that a majority of the House of Lords says that the procedure falls within Section 1(1).

Although the RCN case is an important statement of the meaning of Section 1(1), it leaves some important questions unanswered.

It is plain that "accepted medical practice" itself cannot be the correct test, unless it is to be read as "medical practice accepted by the courts". The main difficulty with making "accepted medical practice" the touchstone of appropriate delegation is that the Act itself puts obvious limits on the use of that idea. Suppose that it became the majority opinion amongst gynaecologists that all steps in an abortion should be performed by nurses. It would then, in a sense, be "accepted medical practice" that nurses should perform all steps. But that would be prohibited by the Act. It could not be legally accepted medical practice. Medical practice looks to the law to determine what is acceptable, not vice versa. ${ }^{3}$ Any test that requires the law to defer entirely to medical practice in determining the correct construction of the Act must be a wrong test. Although in other areas of the law (notably clinical negligence), the law has great respect for the views of responsible medical practitioners, and is importantly (and often decisively) informed by those views, it has long been one of the pillars of medical law that the courts, not the profession, set the standard. If that is true of standard setting in the common law, still more should it be true of statutory construction.

So what must have been meant was "legally acceptable" medical practice. On the facts considered in the RCN case, it was found that the medical induction procedure was acceptable and accordingly fell within the boundaries of $\mathrm{s}$. 1(1).

If it is legitimate to use accepted (or acceptable) medical practice as the arbiter of legality, it is strongly arguable that the relevant medical practice for the purposes of determining legality is the practice known about or envisaged by Parliament at the time of the enactment. As Lord Denning pointed out in the Court of Appeal, had Parliament intended to make the standard move with shifting medical practice, there were plenty of expressions available which would have had that effect. Surgical termination using modern methods was not amongst the procedures envisaged, and it was certainly not foreseen or foreseeable that it might be suggested that nurses might be significant operators in such procedures.

The dissenting views cannot merely be discounted. They emphasised, very powerfully, the need for great caution in the construction of the statute, and in particular the need for judges to be careful not to usurp the function of Parliament and engage in judicial legislation. The danger of such judicial legislation is particularly acute since it is a long time since the Abortion Act 1967 was enacted; abortion practice has changed immeasurably since Parliament debated and voted.

The RCN case draws no distinction in principle between medical and surgical abortion. But that does not mean that all acts which are done or it is envisaged might be done by nurse in the performance of surgical abortions fal within the boundaries of appropriate delegation That is the basic error into which Argent and Pavey fall.

So: does the RCN case say that it is lawful for nurses to perform surgical abortion? No, it does not. The position in relation to nurses involvement in procedures other than that specifically considered in the RCN case is wholly unclear. It would be very unsafe for anyone to act on the basis of the assertions in the Argent and Pavey article. If it is seriously proposed that nurses should perform surgical abortions then the matter should be considered again by Parliament. A ruling on the point by any court lower than the House of Lords is unlikely to give an answer sufficiently definitive to lay to rest the doubts of those affected by the issue.

Charles Foster, MA(Cantab), MRCVS

Barrister, Outer Temple Chambers, London, UK. E-mail: charles.foster@outertemple.com

\section{References}

Argent V, Pavey L. Can nurses legally perform surgical induced abortion? J Fam Plann Reprod Health Car 2007; 33: 79-82.

2 Royal College of Nursing v DHSS [1981] 1 AC 800; p.

3 Note, for example, Bolitho v City and Hackney Health Australia in Rogers v Whitaker (1992) 109 ALR 625.

\section{Reply}

Charles Foster's critique is useful and agrees that abortion law should be modernised. The Abortion Act 1967 does not reflect the realities of current clinical practice and the increasing role of nurses in the provision of abortion care.

The statute could be changed but a test case in the House of Lords or even a ruling from the Department of Health would suffice. Pro-choice and anti-abortion groups hold opposing views on how the law should be changed but it is importan that a new approach reflects modern clinica need.

Foster does state that the RCN case draws no distinction in principle between surgical and medical abortion and this is, in fact, the hub of our argument. In other jurisdictions, nurses and other providers are already providing a safe surgical service. This will assume increasing importance in the UK where the Royal College of Obstetricians and Gynaecologists has recognised doctors' relative disinterest in providing this essential service to women.

Foster considers that accepted medical practice should by judged by the courts but we know that sensible judges do take a pragmatic view based on medical expert opinion.

The Abortion Act was designed to remove the mischief of unsafe abortion and it is now clea that a safe service can be run by nurses who are part of a team under the overall supervision of a medical practitioner.
Vincent Argent, FRCOG, LLB

Consultant Obstetrician and Gynaecologist (Lead in Sexual Health), Addenbrooke's Cambridge University Teaching Hospital, Cambridge,UK.E-mail:Vargent1@aol.com

Lin Pavey, RGN

Member of RCN Nurses Working in Termination of Pregnancy Network

\section{Unsafe abortion in Nigeria}

Each minute of every day, nearly 40 women undergo dangerous, unsafe abortions. ${ }^{1}$ These unsafe abortions are often performed by unskilled providers or under unhygienic condition or both. Estimates based on figures for 2000 indicate that 19 million unsafe abortions take place each year and an estimated 68000 women die as consequences of unsafe abortion, and almost all occur in developing countries. ${ }^{2}$

In Nigeria, as is also the case in most developing countries, unsafe abortion has assumed a serious public health problem, and induced unsafe abortion has been established as an important contributor to maternal morbidity and mortality. In Nigeria, induced abortion is a criminal offence both for the seeker and the provider. The penalty is 14 and 7 years jail sentences, respectively, for the provider and client. These penalties notwithstanding, induced unsafe abortions are still performed on a daily basis both by skilled and unskilled personnel. There are approximately 610000 abortions performed in Nigeria annually with an abortion rate of 25.4 per 1000; of these, $60 \%$ are thought to be unsafe. ${ }^{3}$ In Nigeria, unsafe abortion contributes up to $20 \%$ of maternal mortality, and those women that survive are faced with complications such as sepsis, vesicovaginal fistula, anaemia, ruptured uterus (sometimes ending in hysterectomy), amongst others.

Factors associated with this high morbidity and mortality from unsafe abortion in Nigeria include restrictive abortion law, activity of quacks and untrained providers, poor healthseeking behaviour of women, poor and inadequate post-abortion care facilities in health institutions, inadequate access to family planning counselling, information and services and poor socioeconomic status of Nigerian women.

This suffering and these deaths are preventable and the solutions are well known, available, practical and cost-effective, but they are too often neglected because of political and social constraints. The abortion law in force in Nigeria today is still the one adopted from the British colonial government of 1861. No reasonable amendment or modification has been made to keep apace with time. The existing abortion law prevents the institutionalisation of safe abortion practices and drives abortion underground, thereby encouraging the use of quacks and unqualified providers who cause distress and suffering to the women concerned. It also restricts counselling and training of health professionals on abortion-related issues.

Post-abortion care, an unfortunately neglected vital tool of the reproductive health care package for Nigerian women, should be seriously revisited, revitalised and promoted in Nigeria as a very important intervention strategy to deal with complications arising from unsafe abortions. Women who have unintended pregnancies should have ready access to reliable information and compassionate counselling. In all cases, women should have access to quality services for the management of complications of abortion. Where the law permits, there should be provision of quality standards for abortion providers.

The 1994 International Conference on Population and Development in Cairo, Egypt, at which Nigeria was a participant, agreed that in order to reduce the morbidity and mortality from 